\title{
Model Based Adaptive Direct Power Control for Three-Level NPC Converters
}

\author{
Ramon Portillo, Member, IEEE, Sergio Vazquez, Member, IEEE, Jose I. Leon, Member, IEEE, \\ Maria M. Prats, Member, IEEE, Leopoldo G. Franquelo, Fellow, IEEE
}

\begin{abstract}
In this work, a Model Based Adaptive Direct Power Control (MB-ADPC) with constant switching frequency for Three-Phase Three-Level Neutral Point Clamped (3L-NPC) converters is proposed. The rectifier and inverter operation mode are used to illustrate the flexibility of the proposed MB-ADPC controller. The control design process is based on the continuous averaged model of the system. Depending on the operation mode different control objectives have to be guaranteed. The proposed controller ensures the voltage regulation of the dc-link capacitors for the rectifier operation mode and to achieve voltage balance in the dc-link capacitors and the active and reactive power tracking for the rectifier and inverter operation modes. In addition, adaptive techniques are used to avoid system parameters uncertainties as smoothing inductors and grid frequency values. This work shows that the application of advanced control strategies based on the system model allows enhancing the performance of the overall system. The details of the controllers design process and the experimental results using a $50 \mathrm{kVA}$ Three-Phase ThreeLevel NPC prototype are presented in this paper validating the proposed controllers.
\end{abstract}

Index Terms-Power Electronics Converters, Power Conversion, AC-DC Power Converters, DC-AC Power Converters, Multilevel Converters, Neutral Point Clamped Converter, Power Control, Model Based Adaptive Direct Power Control, Digital Control, Digital Signal Processors, Pulse Width Modulation Converters, Space Vector PWM

\section{INTRODUCTION}

$\mathbf{C}$ ONTINUOUS increasing of power ratings in medium and high voltage applications has stimulated the use of multilevel power electronic converters, resulting in the development of new topologies and their associated control strategies. Neutral Point Converter (NPC) is one of the most used multilevel power electronic converter topologies [1]-[6].

Several control strategies have been proposed for this topology working as a synchronous rectifier or as a grid interface converter. These strategies usually are extensions from the two-level converter controllers but adding the specific particularities of the multilevel systems as the dc-link capacitor voltage balance problem. The control strategies can be distinguished between the current based controllers [7]-[10] and the direct power controllers [11]-[25].

Direct Power Control (DPC) is a well known efficient control strategy for electronic power converters where the instantaneous reactive power theory introduced by Akagi et al is used [26]. This strategy is based on the evaluation of the active and reactive instantaneous power errors values and the voltage vector position [11], [12] or on the Virtual-Flux vector position [13], [14] without any internal control loop for the currents. The main objective of basic DPC technique is to choose, through a Look Up Table (LUT), the best state of the power semiconductors among the possible states in order to achieve instantaneous active and reactive power tracking towards their references. The use of simple and efficient DPC techniques in different industrial applications permits to achieve good dynamics performance and near unity power factor.

One drawback of DPC controllers is that it has not a constant switching frequency. However, this fact can be solved by using Pulse Width Modulation (PWM), Space Vector Modulation (SVM) or predictive control strategies with constant switching frequency [16]-[23], [27], [28]. In this work, the proposed MB-ADPC strategy is combined with an efficient 3D Space Vector Modulation (3D-SVPWM) technique for multilevel converters introduced in [27]. The high gain of the controller is the main drawback of basic DPC formulation and consequently, the values of the input inductors have to be very large to attenuate the current ripple, increasing the cost, size and weight of the system. In order to reduce the input inductors values, LCL filters have been proposed to connect the power converter to the grid [24], [25]. That solution has the drawback of the filter resonance so it has to be well studied. The proposed strategy is implemented as an indirect control through the SVM modulator avoiding the high gain of the direct DPC implementations based on LUTs. This fact permits to concentrate the harmonic spectrum around the switching frequency, simplifying the grid connection filter design and reducing its size, weight and economical cost.

The main contribution of this work is the design of a SVM based MB-ADPC strategy for three-phase three-level NPC power converters including the dc-link voltage balancing loop controller based on a resonant filter to compensate the steady state periodic oscillations. The controller design is based in the converter model [29], and supported by adaptive strategies [7] presented in previous works, improving the performance of three-level three-phase voltage source inverters working in direct power control mode. The MB-ADPC strategy proposed 
is an extension of the controller presented in [15] for the two-level converter. When compared with controllers based on current loops, the proposed controller presents faster response in transients as it is based on DPC strategies. Besides, when compare with basic DPC formulation, the proposed controller presents constant switching frequency, because of SVM-PWM modulation technique is used. The controller design is based on the averaged continuous model of the converter [29], allowing to design the dc-link voltage balance loop with modern control techniques, avoiding the use of LUTs and redundance state space vectors as in previous works. In addition, due to the proposed model based adaptive law that has been included in the controller design, the behavior of the system is robust and hence less sensitive to system parameters values uncertainties and variations.

Due to the interest of the rectifier and inverter operation modes [1]-[5], and to show the flexibility of the proposed MB-ADPC controller, both operation modes are presented.

This paper is organized as follows: In section II, it is introduced the mathematical model of the three-phase three-level NPC power converter. The design process of the proposed MBADPC controller is based on the continuous averaged model of the system and it is described in the section III. Later, in order to verify the theoretical study that has been presented in previous sections, the proposed MB-ADPC controller is compared to those obtained with classic current PI controllers and the experimental results are shown in section IV beside the details of the digital control implementation [30]. Finally, the conclusions of the proposed work are addressed in section V.

\section{Model OF THE SySTEM}

Fig. 1 depicts the generic electrical scheme of a threephase three-level NPC converter. The converter is connected to the grid through smoothing inductors $L$, and the dc-link is composed by a two capacitors voltage divider. Table I summarize the system variables and parameters.

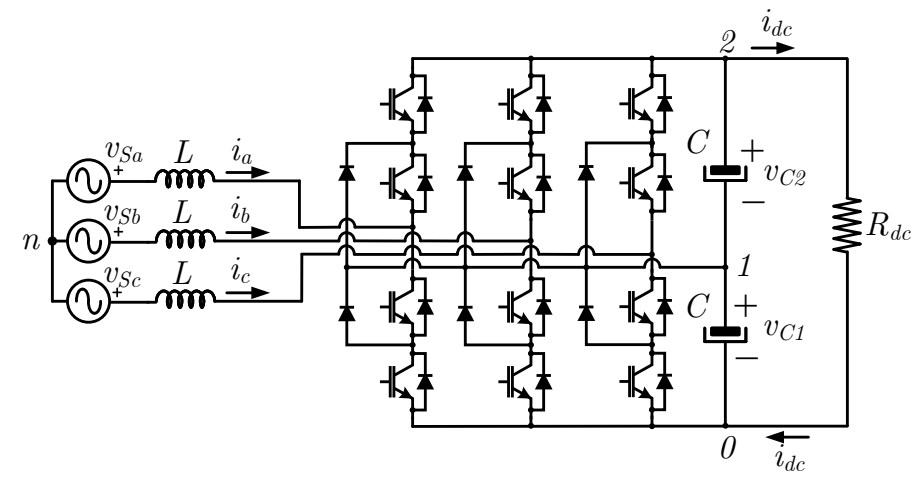

Fig. 1. General Three-Phase Three-Level NPC converter scheme with the notation criterion used to derive the model.

A suitable dynamics model of the system can be obtained following the procedure described in [29]. This modeling technique consists on to obtain the exact time varying averaged model being the resulting equations linear piece wise for NPC topology. In order to obtain a unique set of valid equations all
TABLE I

SYSTEM VARIABLES AN PARAMETERS

\begin{tabular}{cc}
\hline \hline Variable & Description \\
\hline$v_{S a b c}=\left\{v_{S a}, v_{S b}, v_{S c}\right\}^{T}$ & Grid voltage vector in $a b c$ reference frame \\
$v_{S \alpha \beta}=\left\{v_{S \alpha}, v_{S \beta}\right\}^{T}$ & Grid voltage vector in $\alpha \beta \gamma$ reference frame \\
$i_{a b c}=\left\{i_{a}, i_{b}, i_{c}\right\}^{T}$ & Inductors currents in $a b c$ reference frame \\
$i_{\alpha \beta}=\left\{i_{\alpha}, i_{\beta}\right\}^{T}$ & Inductors currents in $\alpha \beta \gamma$ reference frame \\
$\delta_{a b c}=\left\{\delta_{a}, \delta_{b}, \delta_{c}\right\}^{T}$ & Averaged duty cycles in $a b c$ reference frame \\
$\delta_{\alpha \beta}=\left\{\delta_{\alpha}, \delta_{\beta}\right\}^{T}$ & Averaged duty cycles in $\alpha \beta \gamma$ reference frame \\
$v_{C 1}, v_{C 2}$ & dc-link capacitors voltages \\
$L, C$ & Smoothing inductor and dc-link capacitor \\
$\omega$ & Grid voltage source frequency \\
\hline \hline
\end{tabular}

over the range of control averaged signals, quadratic approximations are made and finally the system can be described with one set of equations in the natural coordinates reference frame.

In the systems where the absence of fourth wire makes the homopolar currents to be zero, it is usual to reduce the system equations through a reference frame change. However, in this modeling technique, the principal purpose of the transformation is not to reduce the system equations but, as it will be explained later, to make explicit the relation between component and the dc-link voltages balancing problem.

Following the modeling strategy described in [29] and taking into account the sign criterion shown in Fig. 1, the inductors currents, the sum and the difference of the dc-link voltages dynamics in $a b c$ reference frame can be expressed as (1), (2) and (3), respectively:

$$
L \frac{d}{d t} i_{a b c}=v_{S a b c}-\frac{1}{6}\left(\begin{array}{rrr}
2 & -1 & -1 \\
-1 & 2 & -1 \\
-1 & -1 & 2
\end{array}\right)\left(\begin{array}{ll}
\delta_{a} & \delta_{a}^{2} \\
\delta_{b} & \delta_{b}^{2} \\
\delta_{c} & \delta_{c}^{2}
\end{array}\right)\left(\begin{array}{l}
x_{1} \\
x_{2}
\end{array}\right)
$$

$$
\begin{aligned}
& C \dot{x}_{1}=\delta_{a b c}^{T} i_{a b c}-2 i_{d c} \\
& C \dot{x}_{2}=\left(\delta_{a b c}^{2}\right)^{T} i_{a b c}
\end{aligned}
$$

where $x_{1}=v_{C 2}+v_{C 1}$ and $x_{2}=v_{C 2}-v_{C 1}$ have been introduced because they are more suitable for the controller design since they are directly related with the control objectives.

Vectors originally in $a b c$ reference frame are transformed into $\alpha \beta \gamma$ reference frame using the power-invariant transformation defined by the transformation matrix in (4).

$$
\mathbf{T}_{a b c}^{\alpha \beta \gamma}=\sqrt{\frac{2}{3}}\left(\begin{array}{ccc}
1 & -1 / 2 & -1 / 2 \\
0 & \sqrt{3} / 2 & -\sqrt{3} / 2 \\
1 / \sqrt{2} & 1 / \sqrt{2} & 1 / \sqrt{2}
\end{array}\right)
$$

Applying this transformation to equations (1), (2) and (3) yields the equations (5), (6) and (7) which represent the system 
dynamics in the $\alpha \beta \gamma$ reference frame.

$$
L \frac{d}{d t} i_{\alpha \beta}=v_{S \alpha \beta}-\frac{1}{2} x_{1} \delta_{\alpha \beta}+\left[\begin{array}{c}
\frac{1}{2 \sqrt{6}}\left(\delta_{\beta}^{2}-\delta_{\alpha}^{2}\right)-\frac{1}{\sqrt{3}} \delta_{\alpha} \delta_{\gamma} \\
\frac{\delta_{\alpha} \delta_{\beta}}{\sqrt{6}}-\frac{\delta_{\beta} \delta_{\gamma}}{\sqrt{3}}
\end{array}\right] x_{2}
$$

$$
\begin{aligned}
& C \dot{x}_{1}=\delta_{\alpha \beta}^{T} i_{\alpha \beta}-\frac{2}{R_{d c}} x_{1} \\
& C \dot{x}_{2}=\frac{2}{\sqrt{6}}\left[\delta_{\alpha}^{2}-\delta_{\beta}^{2},-\delta_{\alpha} \delta_{\beta}\right] i_{\alpha \beta}+\frac{1}{\sqrt{6}} \delta_{\alpha \beta}^{T} i_{\alpha \beta} \delta_{\gamma}
\end{aligned}
$$

Notice that in these equations subscript $\gamma$ does not appear in the current and source voltage vectors since there is not fourth wire and the source voltage is supposed to be symmetric and balanced. Equation (7) shows the dynamics of the difference of the converter capacitors voltages and it can be seen that the control signal $\delta_{\gamma}$ has a direct effect over the dynamics of $x_{2}$.

In order to get a correct converter operation, $x_{2}$ must be near zero but can be assumed that it is at least one order of magnitude lower than $x_{1}$. In addition, the averaged duty cycles $\delta_{\alpha \beta}$ are defined as values in $[-1,1]$ range so the third term in the right hand side of the equation (5) can be assumed to be two order of magnitude lower than the second term. With this consideration, the inductor currents dynamics can be approximated by (8).

$$
L \frac{d}{d t} i_{\alpha \beta}=v_{S \alpha \beta}-\frac{1}{2} x_{1} \delta_{\alpha \beta}
$$

The generic converter model given by the equations (8), (6) and (7) will be used in the next sections to design the controllers.

\section{CONTROLLER DESIGN}

In general, the control objectives of the controller can be stated as follows:

i) The instantaneous active power $p$ and the instantaneous reactive power $q$ should track their references, $p^{*}$ and $q^{*}$ respectively, which are calculated in such way that the sum of the capacitor output voltages is regulated towards its reference.

$$
\begin{aligned}
& p \rightarrow p^{*} \\
& q \rightarrow q^{*}
\end{aligned}
$$

Thus, DPC strategy controls indirectly the currents provided by the source through the values of the instantaneous active and reactive power.

ii) The sum of the converter capacitors voltages should be regulated towards its reference.

$$
x_{1} \rightarrow x_{1}^{*}=V_{d c}
$$

iii) The difference of the converter capacitors voltages should be controlled to balance the capacitors voltages values.

$$
x_{2} \rightarrow x_{2}^{*}=0 \mathrm{~V}
$$

Given the control objectives, the proposed controller for the system (6)-(8) is composed of an instantaneous power tracking loop, a voltage regulation loop and a voltage balance loop. In what follows the design of the three control stages is described.

\section{A. Instantaneous power tracking control loop}

The objective of the instantaneous power tracking loop is to guarantee tracking of $p$ and $q$ towards their references. To design this control loop it is assumed that the difference between the capacitors voltages values is small $\left(x_{2} \sim 0\right)$ so the inductors currents dynamics can be approximated by (8). That equation is similar to that from a conventional three-phase two-level converter [15].

Assuming that the input AC voltages are balanced and without harmonic content, and using the instantaneous active (13) and reactive (14) power definition given in [26], the instantaneous active power first derivate over the time, $\dot{p}$, and the instantaneous reactive power first derivative over the time, $\dot{q}$, can be calculated as (15) and (16), respectively.

$$
\begin{aligned}
p & =i_{\alpha \beta}^{T} v_{S \alpha \beta} \\
q & =i_{\alpha \beta}^{T} J v_{S \alpha \beta} \\
L \dot{p} & =\left|v_{S \alpha \beta}\right|^{2}-\frac{1}{2} x_{1} v_{S \alpha \beta}^{T} \delta_{\alpha \beta}+L \omega q \\
L \dot{q} & =-\frac{1}{2} x_{1}\left(J v_{S \alpha \beta}\right)^{T} \delta_{\alpha \beta}-L \omega p
\end{aligned}
$$

Solving the equations (15) and (16) for the condition of $\dot{p}$ and $\dot{q}$ to be zero yields (17) and (18). Those equations represent the two straight lines in the $\alpha \beta$ plane that define the ORS and $c_{1}$ and $c_{2}$ are two variables that represent the displacement over each line. The ORS are composed by four quadrants having each one a different sign combination for the instantaneous active and reactive power derivative.

$$
\begin{aligned}
& O R S_{(\dot{p}=0)}=\frac{2}{x_{1}}\left(\left|v_{S \alpha \beta}\right|^{2}+L \omega q\right) \frac{v_{S \alpha \beta}}{\left|v_{S \alpha \beta}\right|^{2}}+c_{1} J v_{S \alpha \beta} \\
& O R S_{(\dot{q}=0)}=-\frac{2}{x_{1}}(L \omega p) \frac{J v_{S \alpha \beta}}{\left|v_{S \alpha \beta}\right|^{2}}+c_{2} v_{S \alpha \beta}
\end{aligned}
$$

The lines defined by (17) and (18) are perpendicular and intersect in the equilibrium point also known as zero equivalent controller. This equilibrium point is given by (19).

$$
\delta_{\alpha \beta}^{e q}=\frac{2}{x_{1}}\left\{\left(\left|v_{S \alpha \beta}\right|^{2}+L \omega q\right) \frac{v_{S \alpha \beta}}{\left|v_{S \alpha \beta}\right|^{2}}-(L \omega p) \frac{J v_{S \alpha \beta}}{\left|v_{S \alpha \beta}\right|^{2}}\right\}
$$

Taking into account the ORS division defined by (17) and (18) and the equilibrium point (19), the controller (20) is proposed to solve the instantaneous power tracking problem [15].

$$
\begin{aligned}
\delta_{\alpha \beta} & =\delta_{\alpha \beta}^{e q}-k_{p} \tilde{p} v_{S \alpha \beta}-k_{q} \tilde{q} J v_{S \alpha \beta} \\
\tilde{p} & =p^{*}-p \\
\tilde{q} & =q^{*}-q
\end{aligned}
$$

The proposed controller depends on the system parameter values through the expression for the equilibrium point (19), to minimize the effects of the system parameters uncertainties an adaptive law is proposed [31]. The reactance parameter, $X$, is defined as the product of the smoothing inductor and the grid frequency values (21). It is assumed that both parameters are unknown, and the reactance is replaced by its estimated value $\hat{X}$. The error between the actual value of the reactance 
and its estimated value is defined as (22). Taking into account that the actual reactance is assumed to be constant or slowly variant, the error time derivative fulfils (23).

$$
\begin{aligned}
X & =\omega L \\
\tilde{X} & =\hat{X}-X \\
\dot{\tilde{X}} & =\dot{\hat{X}}
\end{aligned}
$$

Replacing $X$ by $\hat{X}$ in (19) is obtained (24), which leads to the new proposed controller (25). Introducing it in (15) and (16) the expressions for the power errors dynamics are derived as (26) and (27).

$$
\begin{gathered}
\left.\hat{\delta}_{\alpha \beta}^{e q}=\frac{2}{x_{1}}\left\{\left(\left|v_{S \alpha \beta}\right|^{2}+\hat{X} q\right) \frac{v_{S \alpha \beta}}{\left|v_{S \alpha \beta}\right|^{2}}-(\hat{X} p) \frac{J v_{S \alpha \beta}}{\left|v_{S \alpha \beta}\right|^{2}}\right\}^{2}\right\} \\
\delta_{\alpha \beta}=\hat{\delta}_{\alpha \beta}^{e q}-k_{p} \tilde{p} v_{S \alpha \beta}-k_{q} \tilde{q} J v_{S \alpha \beta} \\
L \dot{\tilde{p}}=-\frac{x_{1}}{2}\left|v_{S \alpha \beta}\right|^{2} k_{p} \tilde{p}+\tilde{X} q \\
L \dot{\tilde{q}}=-\frac{x_{1}}{2}\left|v_{S \alpha \beta}\right|^{2} k_{q} \tilde{q}-\tilde{X} p
\end{gathered}
$$

A Lyapunov approach has been used for developing an adaptive law to reconstruct parameter $X$. For this purpose, a positive-definite function is proposed, where parameter $\gamma$ is a positive design constant that stands for the adaptation gain. The time derivative of (28) along the trajectories of (26) and (27) is (29) which is made negative-semidefinite by proposing (30) to reconstruct the parameter $\hat{X}$.

$$
\begin{aligned}
& H=\frac{1}{2} L \tilde{p}^{2}+\frac{1}{2} L \tilde{q}^{2}+\frac{1}{2 \gamma} L \tilde{X}^{2} \\
& \dot{H}=-\frac{x_{1}}{2}\left|v_{S \alpha \beta}\right|^{2}\left(k_{p} \tilde{p}^{2}+k q \tilde{q}^{2}\right)+\tilde{X}(q \tilde{p}-p \tilde{q})+\frac{1}{\gamma} \dot{\tilde{X}} \tilde{X}
\end{aligned}
$$

Following Lasalle's theorem arguments, it can be stated that $\tilde{p} \rightarrow 0$ and $\tilde{q} \rightarrow 0$ as $t \rightarrow \infty$ asymptotically. Moreover, from (30) $\tilde{p} \rightarrow 0$ and $\tilde{q} \rightarrow 0$ imply that $\tilde{X}$ is constant. According to (15) and (16) this constant should be zero. This guarantees convergence of the estimated value towards its actual value. Taking into account $\hat{p}$ and $\tilde{q}$ definitions, the parameter $\hat{X}$ can be more convenient reconstructed using expression (31) and hence with (32).

$$
\begin{aligned}
& \dot{\hat{X}}=-\gamma(q \tilde{p}-p \tilde{q}) \\
& \dot{\hat{X}}=-\gamma\left(q p^{*}-p q^{*}\right) \\
& \hat{X}=-\gamma \int\left(q p^{*}-p q^{*}\right) d t
\end{aligned}
$$

Fig. 2 shows the block diagram for the instantaneous power tracking control loop with the adaptive law to estimate the reactance that it is used in determining the equilibrium point.

\section{B. Voltage regulation control loop}

The voltage regulation loop objective is to regulate the sum of the dc-link capacitors voltages. This sum should be maintained equal to the dc-link voltage reference value $V_{d c}$.

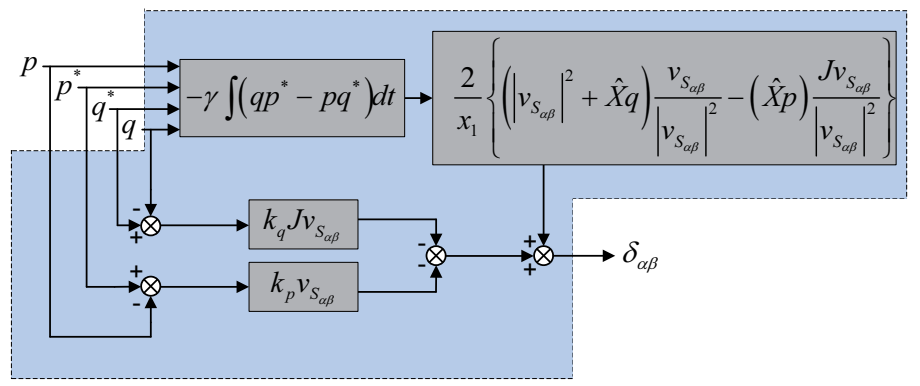

Fig. 2. Block diagram of the instantaneous power tracking control loop.

To design the voltage regulation controller it is assumed that the instantaneous power dynamics are much faster than the dc-link capacitors voltages dynamics that is given by equation (6). Under this assumption, it can be considered that the instantaneous active and reactive power errors are zero so the equivalent controller is (33).

$\hat{\delta}_{\alpha \beta}^{e q}=\frac{2}{x_{1}}\left\{\left(\left|v_{S \alpha \beta}\right|^{2}+\hat{X} q^{*}\right) \frac{v_{S \alpha \beta}}{\left|v_{S \alpha \beta}\right|^{2}}-\left(\hat{X} p^{*}\right) \frac{J v_{S \alpha \beta}}{\left|v_{S \alpha \beta}\right|^{2}}\right\}$

Replacing (33) in (6) yields (34) in which the variable change defined in (35) provide (36).

$$
\begin{aligned}
& C 2 x_{1} \dot{x}_{1}=-\frac{4}{R_{d c}} x_{1}^{2}+4 p^{*} \\
& z_{1}=x_{1}^{2} \\
& C \dot{z}_{1}=-\frac{4}{R_{d c}} z_{1}+P
\end{aligned}
$$

The equation (36) describes the dynamics of a first order LTI system with $P$ as control signal which can be solved with the proposed $P I$ controller in (37).

$$
\begin{aligned}
& P=K_{p} \chi+K_{i} \xi \\
& \tau \dot{\chi}=-\chi+\tilde{z}_{1} \\
& \dot{\xi}=\tilde{z}_{1}
\end{aligned}
$$

In (37) a low pass filter has been included in the proportional term to reduce the high frequency noise and to guarantee a lower dynamics for $x_{1}$ than for the instantaneous active and reactive power. The parameters $K_{p}, K_{i}$ and $\tau$ are design positive non-zero constants.

Finally, Fig. 3 show the block diagram for the voltage regulation loop designed in this section.

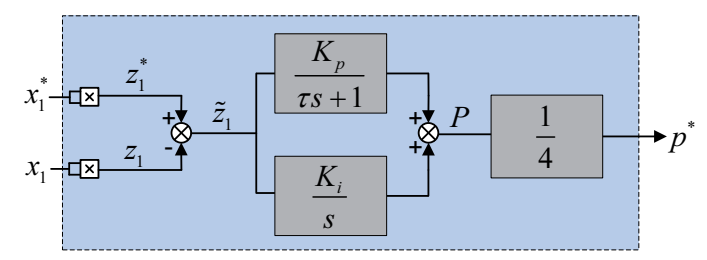

Fig. 3. Block diagram of the voltage regulation loop. 


\section{Voltage balance control loop}

The voltage balance loop objective is to control the difference of the dc-link capacitors voltages values. This difference should be maintained round to zero to ensure that no significant unbalance is present at the dc-link capacitors. As for the regulation loop, it is assumed that the instantaneous power dynamics are much faster than $x_{2}$ dynamics (7), thus (33) can be considered as equivalent controller. Introducing (33) in (7), the voltage balance dynamics can be reduced to (38) where function $\phi(t)$ is defined in (39) and has the expanded form shown in (40).

$$
\begin{gathered}
\begin{aligned}
C \dot{x}_{2}= & \frac{2 p^{*}}{\sqrt{6} x_{1}} \delta_{\gamma}+\phi(t) \\
\phi(t)= & \frac{2}{\sqrt{6}}\left[\left(\delta_{\alpha}^{e q}\right)^{2}-\left(\delta_{\beta}^{e q}\right)^{2},-\delta_{\alpha}^{e q} \delta_{\beta}^{e q}\right] i_{\alpha \beta} \\
\phi(t)=\frac{8}{x_{1}^{2} \sqrt{6}}( & \left(1+\xi_{q}^{2}+2 \xi_{q}-\xi_{p}^{2}\right)\left(v_{S \alpha}^{2}-v_{S \beta}^{2}\right) i_{\alpha} \\
& +4\left(1+\xi_{q}\right) \xi_{p} v_{S \alpha} v_{S \beta} i_{\alpha} \\
& -\left(1+\xi_{q}-\xi_{p}\right) v_{S \alpha} v_{S \beta} i_{\beta} \\
& \left.-\left(1+\xi_{q}\right) \xi_{p}\left(v_{S \beta}^{2}-v_{S \alpha}^{2}\right) i_{\beta}\right) \\
\text { where } & \hat{X} p \\
\xi_{p}= & \frac{\hat{X} q}{\left|v_{S \alpha \beta}\right|^{2}} \text { and } \xi_{q}=\frac{\hat{X}}{\left|v_{S \alpha \beta}\right|^{2}}
\end{aligned}
\end{gathered}
$$

It can be noticed that (38) yields to the same conclusion pointed out in [7], that is, the voltage balance can be controlled with $\delta_{\gamma}$. To achieve this objective, the controller (41) is proposed, where $K_{p x_{2}}$ is a design positive nonzero constant and $\phi(t)$ has been considered as a perturbation. This controller in close loop with (7) ensures that $x_{2}$ tends exponentially towards to zero.

$$
\begin{aligned}
& v_{\gamma}=K_{p x_{2}} \tilde{x}_{2}-\phi(t) \\
& v_{\gamma}=\frac{2 p^{*}}{\sqrt{6} x_{1}} \delta_{\gamma} \\
& \tilde{x}_{2}=x_{2}^{*}-x_{2}
\end{aligned}
$$

To avoid the parameter uncertainties in the $\phi(t)$ calculation, an adaptive law is adopted and the estimated value $\hat{\phi}(t)$ is used to calculate the control action (44).

$$
v_{\gamma}=K_{p x_{2}} \tilde{x}_{2}-\hat{\phi}(t)
$$

From (40) it can be noticed that $\phi(t)$ is a sum of the terms $v_{S \alpha}^{2} i_{\alpha}, v_{S \beta}^{2} i_{\alpha}, v_{S \alpha} v_{S \beta} i_{\alpha}, v_{S \alpha} v_{S \beta} i_{\beta}, v_{S \alpha}^{2} i_{\beta}$ and $v_{S \beta}^{2} i_{\beta}$. If it is supposed that $v_{S \alpha \beta}$ and $i_{\alpha \beta}$ are composed only by fundamental harmonic, $\phi(t)$ can be considered to be mainly composed of fundamental and third harmonics, so both of them, the perturbation and its estimation, can be expressed as (45).

$$
\hat{\phi}(t)=\sum_{k=1,3} \rho_{k}^{T} \hat{\Phi}_{k}, \rho_{k}=\left[\begin{array}{c}
\cos (k \omega t) \\
\sin (k \omega t)
\end{array}\right], \hat{\Phi}_{k}=\left[\begin{array}{c}
\hat{\Phi}_{k}^{r} \\
\hat{\Phi}_{k}^{i}
\end{array}\right]
$$

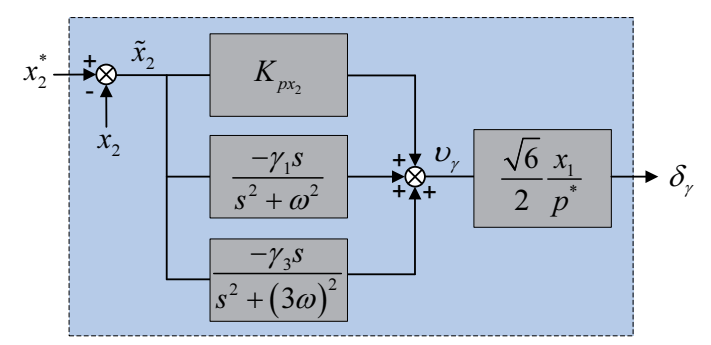

Fig. 4. Block diagram of the voltage balance loop.

Introducing the proposed controller (44) in (7), the $x_{2}$ error dynamics is described by (46).

$$
\begin{aligned}
C \tilde{\dot{x}}_{2} & =-K_{p x_{2}} \tilde{x}_{2}+\tilde{\phi}(t) \\
\tilde{\phi}(t) & =\hat{\phi}(t)-\phi(t)
\end{aligned}
$$

Now to obtain the adaptive law to reconstruct $\hat{\phi}(t)$, a Lyapunov approach is followed and the positive-definite function (47) is proposed, where parameter $\gamma_{k}$ is a positive constant that represents the adaptation gain. The time derivative of (47) along the trajectories of (46) is (48) which is made negative-semidefinite by proposing (49) as adaptive law. Assuming that $\phi(t)$ phasor components are constant or slowly variant, this law can be used to reconstruct the parameter $\hat{\phi}(t)$.

$$
\begin{aligned}
& H=\frac{1}{2} C \tilde{x}_{2}^{2}+\sum_{k=1,3} \frac{1}{2 \gamma_{k}} \tilde{\Phi}_{k}^{T} \tilde{\Phi}_{k} \\
& \dot{H}=-K_{p x_{2}} \tilde{x}_{2}^{2}+\sum_{k=1,3} \tilde{x}_{2} \rho_{k}^{T} \tilde{\Phi}_{k}+\sum_{k=1,3} \frac{1}{\gamma_{k}} \dot{\tilde{\Phi}}_{k} \tilde{\Phi}_{k} \\
& \dot{\hat{\Phi}}_{k} \cong \dot{\tilde{\Phi}}_{k}=-\gamma_{k} \tilde{x}_{2} \rho_{k}^{T}
\end{aligned}
$$

The adaptation scheme proposed in (49) can be further simplified following the procedure given in [7]. This yields the following bank of resonant filters (50), which can be used to estimate the perturbation $\phi(t)$.

$$
\hat{\phi}_{k}=\frac{-\gamma_{k} s}{s^{2}+(k \omega)^{2}} \tilde{x}_{2} \quad \text { where } \quad k \in\{1,3\}
$$

The block diagram for the voltage balance loop it is shown in Fig. 4.

\section{EXPERIMENTAL RESULTS}

Several experiments have been carried out in order to validate the proposed controllers for the rectifier and the inverter operation modes. Fig. 5 shows the photography of the three-phase three-level NPC back to back converter used to carry out the experiments. It is composed by two $50 \mathrm{kVA}$ three-phase three-level NPC converters connected through the dc-link, one of them works in the rectifier operation mode and the other one in the inverter operation mode. The controllers and the SV-PWM modulator are implemented in a DSP based platform, using the TI floating point TMS320VC33 running at $50 \mathrm{MHz}$. The gate signals are generated by programmable gate logic devices from the control action calculated by the main DSP. Thanks to the low computational cost of the 3D-SVPWM used for the modulation, no special software 
TABLE II

SYSTEM VARIABLES AND PARAMETERS

\begin{tabular}{c|l|c}
\hline \hline Variable & Description & Value \\
\hline$V_{S i}, V_{S r}$ & Grid voltage & $380 \mathrm{~V}$ RMS \\
$\omega_{i}, \omega_{r}$ & Grid Frequency & $314.15 \mathrm{rad} / \mathrm{s}$ \\
$v_{C 1}^{*}, v_{C 2}^{*}$ & dc-link capacitors voltage reference & $400 \mathrm{~V}$ \\
$C_{i}, C_{r}$ & dc-link capacitors & $3.3 \mathrm{mF}$ \\
$L_{i}$ & Inverter smoothing inductor & $5 \mathrm{mH}$ \\
$L_{r}$ & Rectifier smoothing inductor & $3.5 \mathrm{mH}$ \\
$f_{s w}, f_{s}$ & Switching and sampling frequency & $5.6 \mathrm{kHz}$ \\
\hline
\end{tabular}

optimization is needed so the controllers are directly implemented as described in Figs. 2, 3 and 4. In this way, the proposed MB-ADPC is executed in $2.56 \mu \mathrm{s}$. On the other hand, the conventional PI current controller needs $1.84 \mu \mathrm{s}$. In addition, the dc-link voltage balance loop requires $2.04 \mu \mathrm{s}$ to be executed.

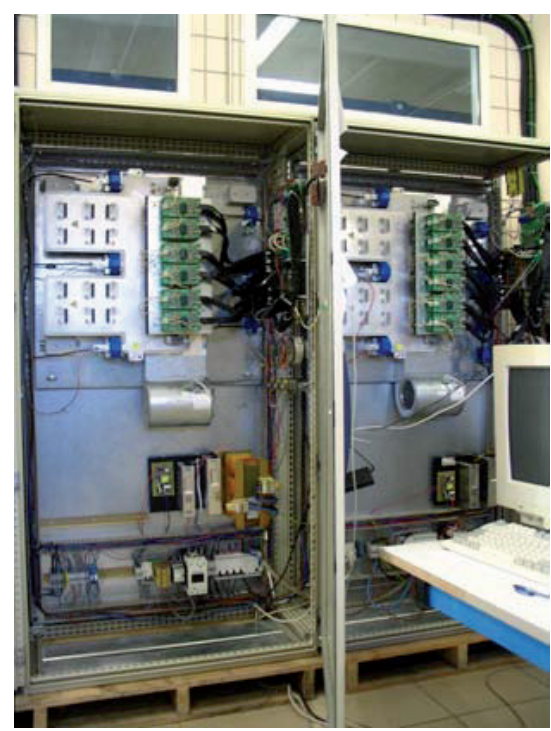

Fig. 5. Photography of the prototype used in the experiments.

Fig. 6 depicts a simplified scheme of the experimental setup, while Table II shows the grid, converters and experiments parameters.

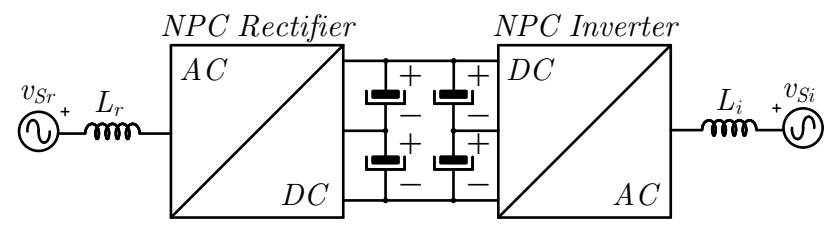

Fig. 6. Electrical scheme for the experimental test bench.

\section{A. Voltage regulation and voltage balance control loops}

In this case, the control objectives for the rectifier side are the voltage regulation and the voltage balance while for the inverter side is only the voltage balance since instantaneous active and reactive power references for the inverter are set externally.
Table III shows the experimentally tuned values for the voltage regulation and voltage balance controllers design constants.

TABLE III

VOLTAGE REGULATION AND BALANCE CONTROL LOOPS DESIGN CONSTANTS VALUES

\begin{tabular}{c|cccccc}
\hline \hline Constant & $K_{p}$ & $K_{i}$ & $\tau$ & $K_{p x_{2}}$ & $\gamma_{1}$ & $\gamma_{3}$ \\
\hline Value & 2 & 0.5 & $1.6 m s$ & 0.1 & 0 & 1500 \\
\hline \hline
\end{tabular}

TABLE IV

MB-ADPC CONTROLLER DESIGN CONSTANTS VALUES

\begin{tabular}{c|ccc}
\hline Constant & $k_{p}$ & $k_{q}$ & $\gamma$ \\
\hline Value & $2 \mathrm{e}-7$ & $0.5 \mathrm{e}-7$ & $1 \mathrm{e}-6$ \\
\hline \hline
\end{tabular}

In Fig. 7, the voltage regulation and the voltage balance control result for the rectifier is shown when an active power step of $10 \mathrm{~kW}$ is applied to the inverter side. In channels 1 and 2 , the dc-link voltages $v_{C 1}$ and $v_{C 2}$ are represented and the voltage unbalance $v_{C 2}-v_{C 1}$ is depicted in math channel. It is shown that the voltage regulation loop works correctly achieving the voltage reference for each part of the dc-link $(400 \mathrm{~V})$ while the voltage balance is always kept round to zero. The obtained results for the inverter side are exactly the same.

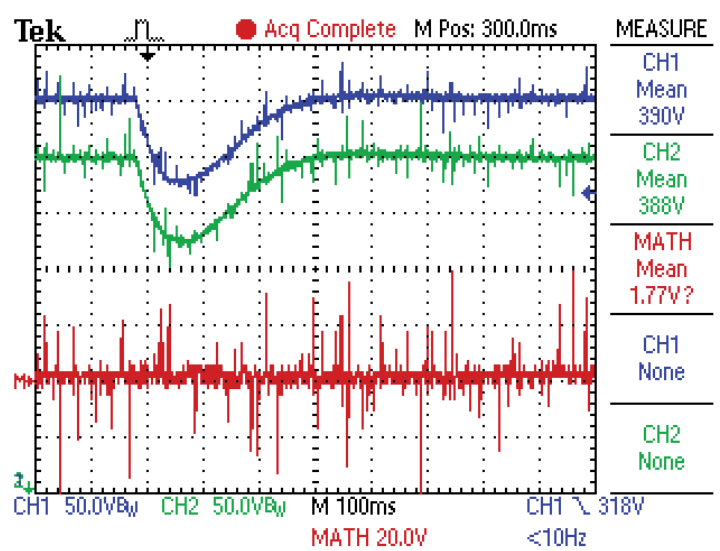

Fig. 7. dc-link capacitor voltages $\left(v_{C 1}, v_{C 2}\right)$ and dc-link voltage unbalance $\left(x_{2}\right)$ in the rectifier side.

\section{B. Instantaneous power control loop}

In this case, the control objective is to achieve the tracking of the active and reactive power towards their references. A comparison with a conventional stationary PI current controller has been carried out to show the enhancement achieved by the proposed MB-ADPC controller scheme. The MB-ADPC controller design constants are shown in Table IV and have been tuned experimentally. The design constants for the PI current controller are summarized in Table V. These values have been determined attending to the Symmetry Optimum criterion [32] and fine tuned experimentally.

In the experiment, several power steps have been applied to the instantaneous active and reactive power references in the 
TABLE V

PI DESIGN CONSTANTS VALUES

\begin{tabular}{l|cc}
\hline \hline Constant & $k_{p_{P I}}$ & $k_{i_{P I}}$ \\
\hline Value & 18 & $1 \mathrm{e}-3$ \\
\hline \hline
\end{tabular}

inverter side. The power steps are sequentially the following: initially zero active and reactive power are injected to the inverter grid side, then the reactive power reference is changed to $10 \mathrm{kVAr}$. After this, the active and reactive power references are changed respectively to $8 \mathrm{~kW}$ and $8 \mathrm{kVAr}$. A third power step is applied imposing that the active and reactive power references are $10 \mathrm{~kW}$ and $0 \mathrm{kVAr}$ respectively. Finally, the system returns to the initial state. This sequence is summarized in Table VI.

TABLE VI

EXPERIMENTAL ACTIVE AND REACTIVE POWER REFERENCES SEQUENCE

\begin{tabular}{l|ccccc}
\hline \hline Step & 1 & 2 & 3 & 4 & 5 \\
\hline$p_{i}^{*}(\mathrm{~kW})$ & 0 & 0 & 8 & 10 & 0 \\
$q_{i}^{*}(\mathrm{kVAr})$ & 0 & 10 & 8 & 0 & 0 \\
\hline
\end{tabular}

In Fig. 8 and Fig. 9, the obtained apparent, active and reactive power trends using the proposed MB-ADPC controller and the stationary classic PI current controller are represented. As expected, the results obtained with the proposed MBADPC are better than those obtained with the stationary PI controller, due to the poor behavior of the PI controller when it is used to tracking time-variant variables [5]. From the experiments carried out and taking into account that the horizontal scale in Figs. 8 and 9 is 8 s/div, it can be noted that when using the proposed MB-ADPC strategy, the transients in the power steps are faster than using the PI controller. In fact for an instantaneous active power reference step from 0 to $10 \mathrm{~kW}$, the power transient slew rate are $7 \mathrm{~kW} / \mathrm{ms}$ and $9 \mathrm{~kW} / \mathrm{ms}$ for PI and MB-ADPC controllers, respectively. In addition, the tracking of the active and reactive power toward their references is clearly improved in steady state with the proposed MB-ADPC controller as can be seen on Table VIII.

In order to show the advantage of the use of the proposed adaptive law for the unknown reactance parameter $X$, an experiment that consists on a step on the instantaneous reactive power reference from 0 to $8 \mathrm{kVAr}$ has been carried out. Fig. 10a shows the trend for the output reactive power of the inverter with a certain value for $\gamma$ while Fig. 10b shows the same for a smaller value. It can be seen that higher this value is, quicker the output reactive power error tends toward zero. However, in the experiments it is observed that higher values of $\gamma$ lead to higher ripples in the currents that make the system unstable. In this way, there is a trade off between the performance and the stability of the system.

Fig. 11 shows the details of the obtained voltages and currents using the proposed MB-ADPC when the instantaneous active and reactive power reference in the inverter side are $p^{*}=8 \mathrm{~kW}$ and $q^{*}=8 \mathrm{kVAr}$, respectively, while Fig. 12 shows the results when using conventional PI currents controller.

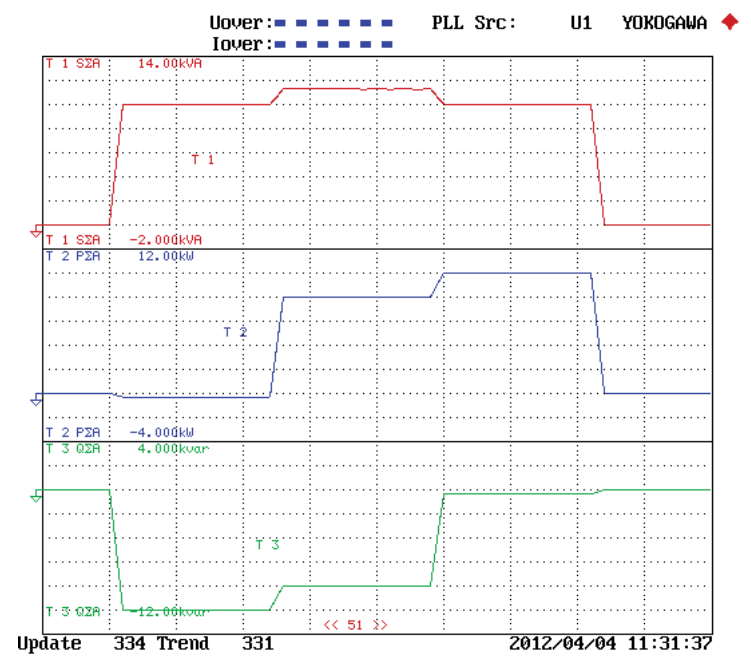

Fig. 8. From top to bottom: Apparent, active and reactive power trends in the inverter side using the proposed MB-ADPC controller. Horizontal scale: 8 s/div.

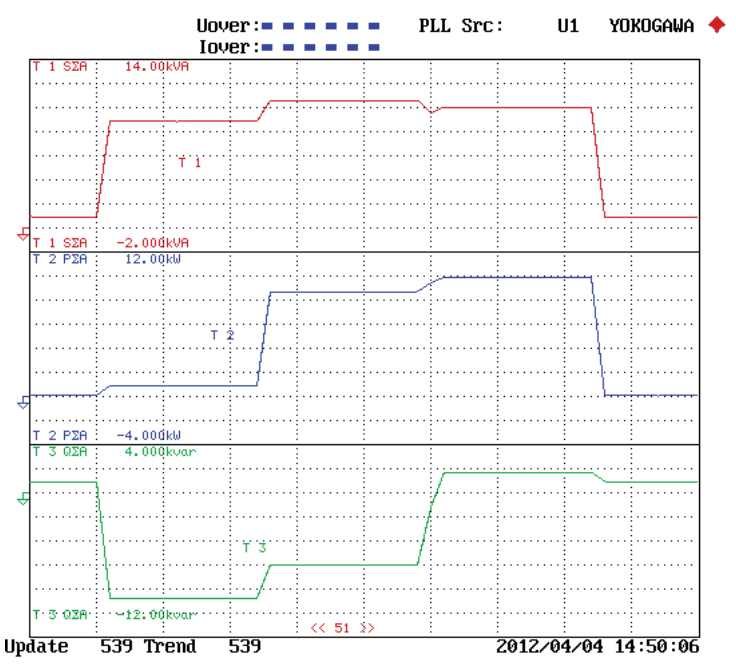

Fig. 9. From top to bottom: Apparent, active and reactive power trends in the inverter side using the stationary PI controller. Horizontal scale: 8 s/div.

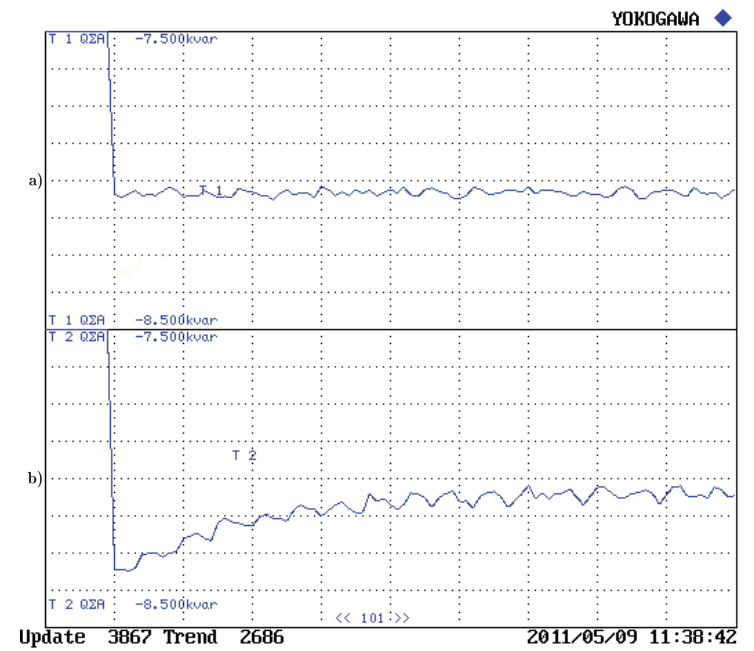

Fig. 10. Reactive power trends in the inverter side using the proposed MBADPC controller during an instantaneous reactive power reference step from $q^{*}=0 \mathrm{kVAr}$ to $q^{*}=8 \mathrm{kVAr}$ with $p^{*}=8 \mathrm{~kW}$ for two different values of the adaptive gain: a) $\gamma=1 \mathrm{e}-6 \mathrm{~b}) \gamma=1 \mathrm{e}-8$. 
TABLE VII

POWER REFERENCES FOR A, B AND C EXPERIMENTS

\begin{tabular}{l|ccc}
\hline \hline & Experiment $A$ & Experiment $B$ & Experiment $C$ \\
\hline$p_{i}^{*}(\mathrm{~kW})$ & 10 & 0 & 8 \\
$q_{i}^{*}(\mathrm{kVAr})$ & 0 & 10 & 8 \\
\hline
\end{tabular}

In order to evaluate the steady state performance of the proposed controllers, a new set of experiments have been carried out. The experiments consist on setting the active and reactive power references to a fixed value and to measure the apparent, active and reactive power plus the THD for the currents. Table VII shows each experiment used power references.

In Table VIII, measurements of the apparent, active and reactive power for the inverter side using the proposed $\mathrm{MB}$ ADPC and the conventional PI current controllers are summarized. It can be seen that in all cases, the power references are achieved but in general using the proposed MB-ADPC controller provides smaller power errors than using the PI. In experiment $A$, the active power error is reduced from $1.21 \%$ to $0.05 \%$. Besides, the reactive power is reduced from 1.642 $\mathrm{kVAr}$ to $-0.372 \mathrm{kVAr}$ what implies a reduction in the reactive power error equal to $77 \%$. Similar results can be observed in experiments $\mathrm{B}$ and $\mathrm{C}$. In addition, it can be seen that both strategies achieve similar THD results. The THD, using the proposed MB-ADPC, for experiments A, B and C, are $3.4 \%$, $3.9 \%$ and $3.6 \%$ respectively, and when the conventional PI is used, $3.1 \%, 5.5 \%$ and $3.7 \%$.

In order to show the effects in the rectifier when the active and reactive power references are changed in the inverter side, measurements in the rectifier have been taken. In Table IX are presented the measurements of the apparent, active and reactive power for the rectifier side converter when the experiments $\mathrm{A}, \mathrm{B}$ and $\mathrm{C}$ are carried out. The rectifier is controlled using the proposed MB-ADPC strategy. From Table IX, it can be noticed that non zero reactive power reference in the inverter side, do not affect to the reactive power consumed

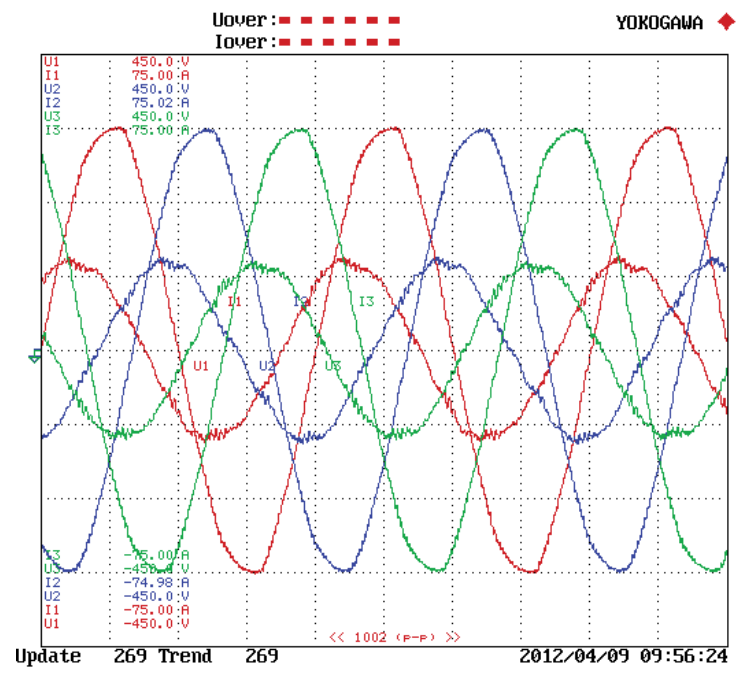

Fig. 11. Experimental voltages and currents waveforms in the inverter side when $p^{*}=8 \mathrm{~kW}$ and $q^{*}=8 \mathrm{kVAr}$ with the proposed MB-ADPC.

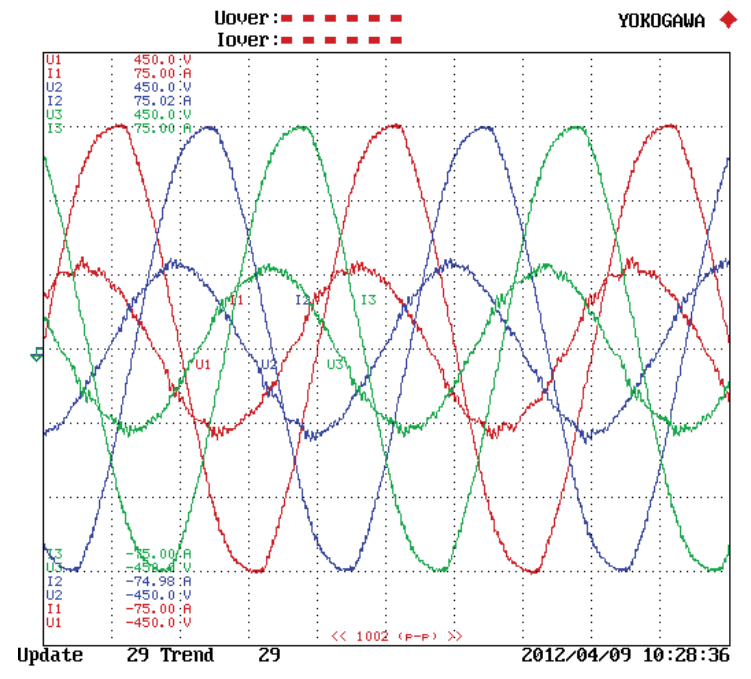

Fig. 12. Experimental voltages and currents waveforms in the inverter side when $p^{*}=8 \mathrm{~kW}$ and $q^{*}=8 \mathrm{kVAr}$ with conventional stationary PI currents controller.

by the rectifier, which is maintained to a low value in all experiments, achieving almost a unity power factor. Besides, it can be observed that the active power consumed by the rectifier is always higher that the active power commanded in the inverter side. This is due to the system power losses that must be provided by the rectifier grid side.

TABLE VIII

EXPERIMENTAL RESULTS FOR A, B AND C EXPERIMENTS. INVERTER SIDE.

\begin{tabular}{lcccccc}
\hline \hline & \multicolumn{2}{c}{ Experiment A } & \multicolumn{2}{c}{ Experiment B } & \multicolumn{2}{c}{ Experiment C } \\
& $D P C$ & $P I$ & $D P C$ & $P I$ & $D P C$ & $P I$ \\
\hline$S(\mathrm{kVA})$ & 10.012 & 10.014 & 9.978 & 8.879 & 11.293 & 10.570 \\
$P(\mathrm{~kW})$ & 10.005 & 9.879 & -0.330 & 0.847 & 7.957 & 8.689 \\
$Q(\mathrm{kVAr})$ & -0.372 & 1.642 & -9.972 & -8.839 & -8.014 & -6.019 \\
$T H D(\%)$ & 3.4 & 3.1 & 3.9 & 5.5 & 3.6 & 3.7 \\
\hline \hline
\end{tabular}

TABLE IX

EXPERIMENTAL RESULTS WITH THE PROPOSED MB-ADPC. RECTIFIER SIDE.

\begin{tabular}{lccc}
\hline \hline & Experiment A & Experiment B & Experiment C \\
\hline$S(\mathrm{kVA})$ & 11.385 & 2.447 & 9.706 \\
$P(\mathrm{~kW})$ & 11.357 & 2.227 & 9.674 \\
$Q(\mathrm{kVAr})$ & 0.230 & 0.276 & 0.239 \\
\hline \hline
\end{tabular}

\section{CONCLUSION}

In this paper, a new adaptive DPC controller for three-phase three-level NPC power converters is proposed. This controller is an extension of the DPC technique applied to two-level converters adding the particularities of three-level topologies. Thanks to continuous averaged model of the system, adaptive techniques have been included in the control design to overcome problems associated with system parameter uncertainties. The experimental results show that the proposed MB-ADPC controller achieves the active and reactive power 
tracking and the regulation and the balance of the dc-link capacitors voltages, improving the overall behavior of the system compared with conventional stationary PI strategies. The good transient and steady state operation of the proposed technique has been evaluated in a $50 \mathrm{kVA}$ back to back threephase three-level NPC prototype. The experimental results show that the grid connection filter can be reduced because the high gain and the harmonic spectrum spread of the classical DPC controller are avoided, due to the SVM applied provides a constant switching frequency. This fact leads to an increase of the operation range of the power converter improving the dynamics of the system. Moreover, the model based voltage balance control loop design, allows the use of modern control techniques, avoiding the use of LUT and sliding mode control techniques based on the multilevel state space vectors redundancy.

\section{REFERENCES}

[1] J. R. Rodriguez, J. W. Dixon, J. R. Espinoza, J. Pontt, and P. Lezana, "Pwm regenerative rectifiers: state of the art," IEEE Transactions on Industrial Electronics, vol. 52, no. 1, pp. 5-22, 2005.

[2] J. Rodriguez, S. Bernet, B. Wu, J. O. Pontt, and S. Kouro, "Multilevel voltage-source-converter topologies for industrial medium-voltage drives," IEEE Transactions on Industrial Electronics, vol. 54, no. 6, pp. 2930-2945, 2007.

[3] S. Alepuz, S. Busquets-Monge, J. Bordonau, J. Gago, D. Gonzalez, and J. Balcells, "Interfacing renewable energy sources to the utility grid using a three-level inverter," IEEE Transactions on Industrial Electronics, vol. 53, no. 5, pp. 1504-1511, 2006.

[4] J. M. Carrasco, E. Galvan, R. Portillo, L. G. Franquelo, and J. T Bialasiewicz, "Power electronic systems for the grid integration of wind turbines," in Proc. IECON 2006 - 32nd Annual Conf. IEEE Industrial Electronics, 2006, pp. 4182-4188.

[5] F. Blaabjerg, R. Teodorescu, M. Liserre, and A. V. Timbus, "Overview of control and grid synchronization for distributed power generation systems," IEEE Transactions on Industrial Electronics, vol. 53, no. 5, pp. 1398-1409, 2006.

[6] T. Atalik, M. Deniz, E. Koc, C. Gercek, B. Gultekin, M. Ermis, and I. Cadirci, "Multi-dsp and -fpga based fully-digital control system for cascaded multilevel converters used in facts applications," Industrial Informatics, IEEE Transactions on, vol. PP, no. 99, p. 1, 2012.

[7] G. Escobar, J. Leyva-Ramos, J. M. Carrasco, E. Galvan, R. C. Portillo, M. M. Prats, and L. G. Franqueto, "Control of a three level converter used as a synchronous rectifier," in Proc. IEEE 35th Annual Power Electronics Specialists Conf. PESC 04, vol. 5, 2004, pp. 3458-3464.

[8] L. Yacoubi, K. Al-Haddad, L.-A. Dessaint, and F. Fnaiech, "Linear and nonlinear control techniques for a three-phase three-level npc boost rectifier,' IEEE Transactions on Industrial Electronics, vol. 53, no. 6, pp. 1908-1918, 2006.

[9] A. Sabanovic, "Variable structure systems with sliding modes in motion control-a survey," IEEE Transactions on Industrial Informatics, vol. 7, no. 2, pp. 212-223, 2011.

[10] C. Xia, M. Wang, Z. Song, and T. Liu, "Robust model predictive current control of three-phase voltage source pwm rectifier with online disturbance observation," Industrial Informatics, IEEE Transactions on, vol. PP, no. 99, p. 1, 2012.

[11] T. Ohnishi, "Three phase pwm converter/inverter by means of instantaneous active and reactive power control,' in Proc. IECON '91. Conf. Int Industrial Electronics, Control and Instrumentation, 1991, pp. 819-824.

[12] J. Eloy-Garcia, S. Arnaltes, and J. L. Rodriguez-Amenedo, "Extended direct power control for multilevel inverters including dc link middle point voltage control," IET Electric Power Applications, vol. 1, no. 4, pp. 571-580, 2007.

[13] M. Malinowski, M. P. Kazmierkowski, S. Hansen, F. Blaabjerg, and G. D. Marques, "Virtual-flux-based direct power control of three-phase pwm rectifiers," IEEE Transactions on Industry Applications, vol. 37, no. 4, pp. 1019-1027, 2001.

[14] L. A. Serpa and J. W. Kolar, "Virtual-flux direct power control for mains connected three-level npc inverter systems," in Proc. Power Conversion Conf. - Nagoya PCC '07, 2007, pp. 130-136.
[15] S. Vazquez, J. I. Leon, J. A. Sanchez, E. Galvan, J. M. Carrasco, L. G. Franquelo, E. Dominguez, and G. Escobar, "Optimized direct power control strategy using output regulation subspaces and pulse width modulation," in Proc. IECON 2006 - 32nd Annual Conf. IEEE Industrial Electronics, 2006, pp. 1896-1901.

[16] T. Noguchi, H. Tomiki, S. Kondo, and I. Takahashi, "Direct power control of pwm converter without power-source voltage sensors," IEEE Transactions on Industry Applications, vol. 34, no. 3, pp. 473-479, 1998.

[17] G. Escobar, A. M. Stankovic, J. M. Carrasco, E. Galvan, and R. Ortega, "Analysis and design of direct power control (dpc) for a three phase synchronous rectifier via output regulation subspaces," IEEE Transactions on Power Electronics, vol. 18, no. 3, pp. 823-830, 2003.

[18] M. Malinowski, M. Jasinski, and M. P. Kazmierkowski, "Simple direct power control of three-phase pwm rectifier using space-vector modulation (dpc-svm)," IEEE Transactions on Industrial Electronics, vol. 51, no. 2, pp. 447-454, 2004.

[19] M. Malinowski, G. Marques, M. Cichowlas, and M. P. Kazmierkowski, "New direct power control of three-phase pwm boost rectifiers under distorted and imbalanced line voltage conditions," in Proc. IEEE Int. Symp. Industrial Electronics ISIE '03, vol. 1, 2003, pp. 438-443.

[20] J. Restrepo, J. Viola, J. M. Aller, and A. Bueno, "A simple switch selection state for svm direct power control," in Proc. IEEE Int Industrial Electronics Symp, vol. 2, 2006, pp. 1112-1116.

[21] S. Aurtenechea, M. A. Rodriguez, E. Oyarbide, and J. R. Torrealday, "Predictive direct power control - a new control strategy for dc/ac converters," in Proc. IECON 2006 - 32nd Annual Conf. IEEE Industrial Electronics, 2006, pp. 1661-1666.

[22] — , "Predictive direct power control of mv grid-connected three-level npc converters," in Proc. IEEE Int. Symp. Industrial Electronics ISIE 2007, 2007, pp. 901-906.

[23] S. A. Larrinaga, M. A. R. Vidal, E. Oyarbide, and J. R. T. Apraiz, "Predictive control strategy for dc/ac converters based on direct power control," IEEE Transactions on Industrial Electronics, vol. 54, no. 3, pp. 1261-1271, 2007.

[24] L. A. Serpa, S. Ponnaluri, P. M. Barbosa, and J. W. Kolar, "A modified direct power control strategy allowing the connection of three-phase inverters to the grid through lcl filters," IEEE Transactions on Industry Applications, vol. 43, no. 5, pp. 1388-1400, 2007.

[25] M. Malinowski, M. P. Kazmierkowski, and S. Bernet, "New simple active damping of resonance in three-phase pwm converter with lcl filter," in Proc. IEEE Int. Conf. Industrial Technology ICIT 2005, 2005, pp. $861-865$.

[26] H. Akagi, Y. Kanazawa, and A. Nabae, "Instantaneous reactive power compensators comprising switching devices without energy storage components," IEEE Transactions on Industry Applications, no. 3, pp. 625-630, 1984.

[27] M. M. Prats, L. G. Franquelo, R. Portillo, J. I. Leon, E. Galvan, and J. M. Carrasco, "A 3-d space vector modulation generalized algorithm for multilevel converters," IEEE Power Electronics Letters, vol. 1, no. 4, pp. 110-114, 2003.

[28] M. P. Kazmierkowski, M. Jasinski, and G. Wrona, "Dsp-based control of grid-connected power converters operating under grid distortions," IEEE Transactions on Industrial Informatics, vol. 7, no. 2, pp. 204-211, 2011.

[29] R. C. Portillo, M. M. Prats, J. I. Leon, J. A. Sanchez, J. M. Carrasco, E. Galvan, and L. G. Franquelo, "Modeling strategy for back-toback three-level converters applied to high-power wind turbines," IEEE Transactions on Industrial Electronics, vol. 53, no. 5, pp. 1483-1491, 2006.

[30] C. Buccella, C. Cecati, and H. Latafat, "Digital control of power converters - a survey," Industrial Informatics, IEEE Transactions on, vol. PP, no. 99, p. 1, 2012.

[31] S. Vazquez, J. A. Sanchez, J. M. Carrasco, J. I. Leon, and E. Galvan, "A model-based direct power control for three-phase power converters," IEEE Transactions on Industrial Electronics, vol. 55, no. 4, pp. 1647$1657,2008$.

[32] M. Jasinski, "Direct power and torque control of ac/dc/ac converterfed induction motor drives," Ph.D. dissertation, POLITECHNIKA WARSZAWSKA, 2005. 


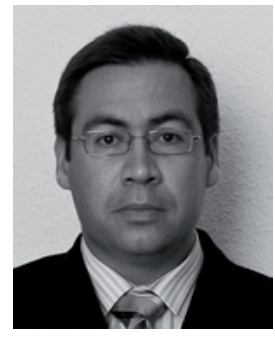

Ramon Portillo (S'06, M'08) was born in Seville, Spain, in 1974. He received the B.S., M.S., and $\mathrm{Ph} . \mathrm{D}$. degrees in electrical engineering from the University of Seville (US), Seville, Spain, in 2001, 2002 and 2012, respectively.

He has been with US since 2001 when he joined the Power Electronics Group, working in R\&D projects, and has been an Assistant Professor with the Department of Electronic Engineering since 2002.

His research interests include electronic power systems applied to energy conditioning and generation, power quality in renewable generation plants, applications of fuzzy systems in industry and wind farms, and modeling and control of power-electronic converters and industrial drives.

He was a co-recipient of the 2008 Best Paper Award of the IEEE Industrial Electronics Magazine and of the 2011 Best Paper Award of the Transactions on Industrial Electronics.

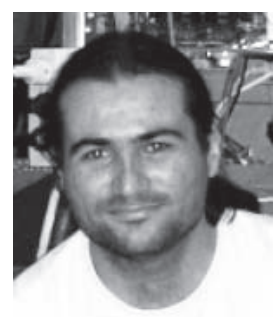

Sergio Vazquez (S'04, M'08) was born in Seville, Spain, in 1974. He received the B.S, M.S. and PhD degrees in industrial engineering from the University of Seville (US) in 2003, 2006 and 2010, respectively.

In 2002, he was with the Power Electronics Group, US, working in R\&D projects. He is currently an Associate Professor with the Department of Electronic Engineering in the US. His research interests include power electronics systems, modeling, modulation and control of power electronics converters applied to renewable energy technologies.

He was a co-recipient of the 2011 Best Paper Award of the Transactions on Industrial Electronics.

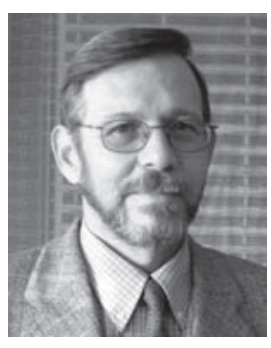

Leopoldo G. Franquelo (M'84, SM'96, F'05) was born in Málaga, Spain. He received the M.Sc. and $\mathrm{Ph} . \mathrm{D}$. degrees in electrical engineering from the Universidad de Sevilla, Seville, Spain in 1977 and 1980 respectively.

In 1978 he joined the Universidad de Sevilla as Research Assistant, being Associated Professor in 1982 and Professor since 1986. Since 1998 till 2005 has been Director of the Electronic Engineering Department.

His technical interests have started in 1978 with Microprocessor Industrial Electronics Applications, evolving to Electronics Power Applications and in the 90's to Application Specific ICs design for the control of Power Converters. His current research interest lies on modulation techniques for multilevel inverters and its application to power electronic systems for renewable energy systems.

He is leading a large research and teaching team in Spain. In the last five years his group activity can be summarized as: 60 Publications in International Journals, 200 in International Conferences, several book chapters, 17 Patents, advisor for $10 \mathrm{PhD}$ dissertations and more than $110 \mathrm{R} \& \mathrm{D}$ projects. His research team has been awarded with the Excellence Status by the Regional Government.

He is IEEE member since 1984, Senior Member since 1996 and Fellow since 2005. He has been Vice-president of the Industrial Electronics Society Spanish Chapter (2002-2003), Member at large of the Industrial Electronics Society AdCom (2002-2003), Vice-President for Conferences (2004-2007), President Elect of the IES (2008-2009), President of the IES (2009-2011) and Past-President of the IES since 2012. Currently is a Distinguished Lecturer since 2006, Associated Editor for the IEEE Transactions on Industrial Electronics since 2007.

He was a co-recipient of the 2008 Best Paper Award of the IEEE Industrial Electronics Magazine, of the 2011 Best Paper Award of the Transactions on Industrial Electronics and recipient of the 2012 IEEE-IES Dr.-Ing. Eugene Mittelmann Achievement Award.

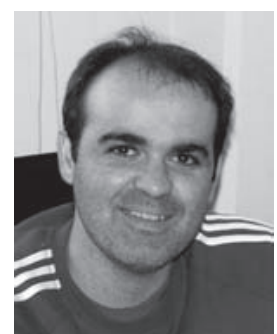

Jose I. Leon (S’04, M’07) was born in Cádiz, Spain, in 1976. He received the B.S., M.S., and Ph.D. degrees in telecommunications engineering from the University of Seville (US), Seville, Spain, in 1999, 2001 and 2006, respectively.

Currently, he is an Associate Professor with the Department of Electronic Engineering, US. His research interests include electronic power systems, modulation and control of power converters, and industrial drives.

Dr. Leon was co-recipient of the 2008 Best Paper Award of the IEEE Industrial Electronics Magazine and of the 2011 Best Paper Award of the Transactions on Industrial Electronics.

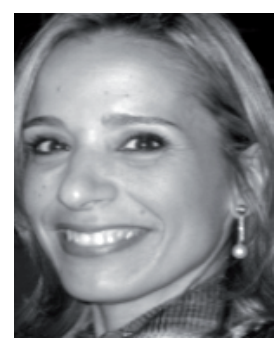

Maria Angeles Martin Prats was born in Seville, Spain, in 1971. She received the Ms. and $\mathrm{PhD}$ degrees from the University of Seville, Spain in 1996 and 2003, respectively, both in physics.

In 1996 she joined the Spanish INTA (Aerospace Technical National Institute), where she was working in the Renewable Energy Department. In 1998, she joined the Department of Electrical Engineering, University of Huelva, Spain. Since 2000 - 2009, she has been an Assistant Professor with Electronic Engineering Department, University of Seville, Spain Since 2009, she is Associate Professor with Electronic Engineering Department, University of Seville and Chair of IEEE Aerospace and electronics Systems Spain. Her research interest focuses on avionics, multilevel converters and fuel cell power conditioner systems. She is involved in industrial applications for the design and development of power converters applied to renewable energy technologies and power electronics and avionics applied to aeronautical and aerospace applications.

She was a co-recipient of the 2008 Best Paper Award of the IEEE Industrial Electronics Magazine. 